\title{
Management of Anesthesia in a Child with a Large Neck Rhabdoid Tumor
}

\author{
Marija Stevic $^{\mathrm{a}}$ Zlatko Bokun ${ }^{\mathrm{c}}$ Irina Milojevic ${ }^{\mathrm{a}}$ Ivana Budic ${ }^{f}$ \\ Branislav Jovanovic ${ }^{b}$ Zoran Krstic $^{d}$ Dusica Simic ${ }^{e}$ \\ Departments of a Anesthesia and ${ }^{b}$ Pediatric Surgery, University Children's Hospital, ' Department of Minimally \\ Invasive Surgery, Zvezdara University Center Belgrade, and Departments of dPediatric Surgery and eAnesthesia, \\ Faculty of Medicine, University of Belgrade, Belgrade, and f Department of Anesthesia, Clinical Centre Nis, Faculty of \\ Medicine, University of Nis, Nis, Serbia
}

\section{Key Words}

Rhabdoid· Neck · Child · Anesthesia

\section{Abstract}

Objective: The aim of this paper was to report the management of anesthesia of a child with a large neck rhabdoid tumor. Clinical Presentation and Intervention: A 9-monthold female patient underwent urgent neck tumor excision due to intratumoral bleeding from a large tumor that compressed and dislocated the trachea; therefore, intubation was expected to be difficult. Sevoflurane inhalation induction was utilized to maintain spontaneous respiration. Oral laryngoscopy revealed Cormack-Lehane grade 3 laryngeal view. The trachea was intubated using a reinforced tube on the third attempt. Fiberoptic bronchoscope-assisted intubation was planned as an alternative in case of conventional intubation failure. Anticipation of massive blood loss necessitated central venous catheterization. Conclusion: Establishing a safe airway, intubation during spontaneous breathing and invasive hemodynamic monitoring are crucial factors in the anesthetic management of pediatric patients with a large neck tumor.

(c) 2015 S. Karger AG, Basel

\section{Introduction}

Extrarenal malignant rhabdoid tumor (MRT) is a rare, highly aggressive childhood tumor with an extremely poor prognosis [1]. It represents less than $1 \%$ of all pediatric soft tissue malignancies, typically involving infants under the age of 1 year [2]. Extrarenal MRT frequently involves locations deep in the neck, abdomen, paranasal and orbital regions [3]. Due to its location, the neck tumor requires delicate surgery and meticulous anesthesia care.

\section{Case Report}

A 9-month-old female patient presented with giant rhabdoid neck mass (fig. 1). She underwent general anesthesia for neck tumor excision after three cycles of chemotherapy using Cooperative Weichteilsarcom Studiengruppe (CWS) guidance, which resulted in reduction of the tumor mass. A computed tomography (CT) scan revealed a significant large protruding mass on the right lateral contour of the neck, which dislocated the trachea to the left and narrowed its lumen in its cranial half (fig. 2). Noticable intratumor bleeding was an indication for urgent surgery. Her preoperative hemoglobin level was $8.5 \mathrm{~g} / \mathrm{dl}$; other laboratory tests were

\begin{tabular}{ll}
\hline KARGER & $\begin{array}{l}\text { C) } 2015 \text { S. Karger AG, Basel } \\
\text { 1011-7571/15/0253-0290\$39.50/0 Oper }\end{array}$ \\
$\begin{array}{l}\text { E-Mail karger@karger.com } \\
\text { www.karger.com/mpp }\end{array}$ & $\begin{array}{l}\text { This is an Open Access article licensed under the terms of the } \\
\text { Creative Commons Attribution-NonCommercial 3.0 Un- } \\
\text { ported license (CC BY-NC) (www.karger.com/OA-license), } \\
\text { applicable to the online version of the article only. Distribu- } \\
\text { tion permitted for non-commercial purposes only. }\end{array}$
\end{tabular}

Marija Stevic, MD

Department of Anesthesia, University Children's Hospital Tirsova 10

RS-11000 Belgrade (Serbia)

E-Mail mamarija74@gmail.com 


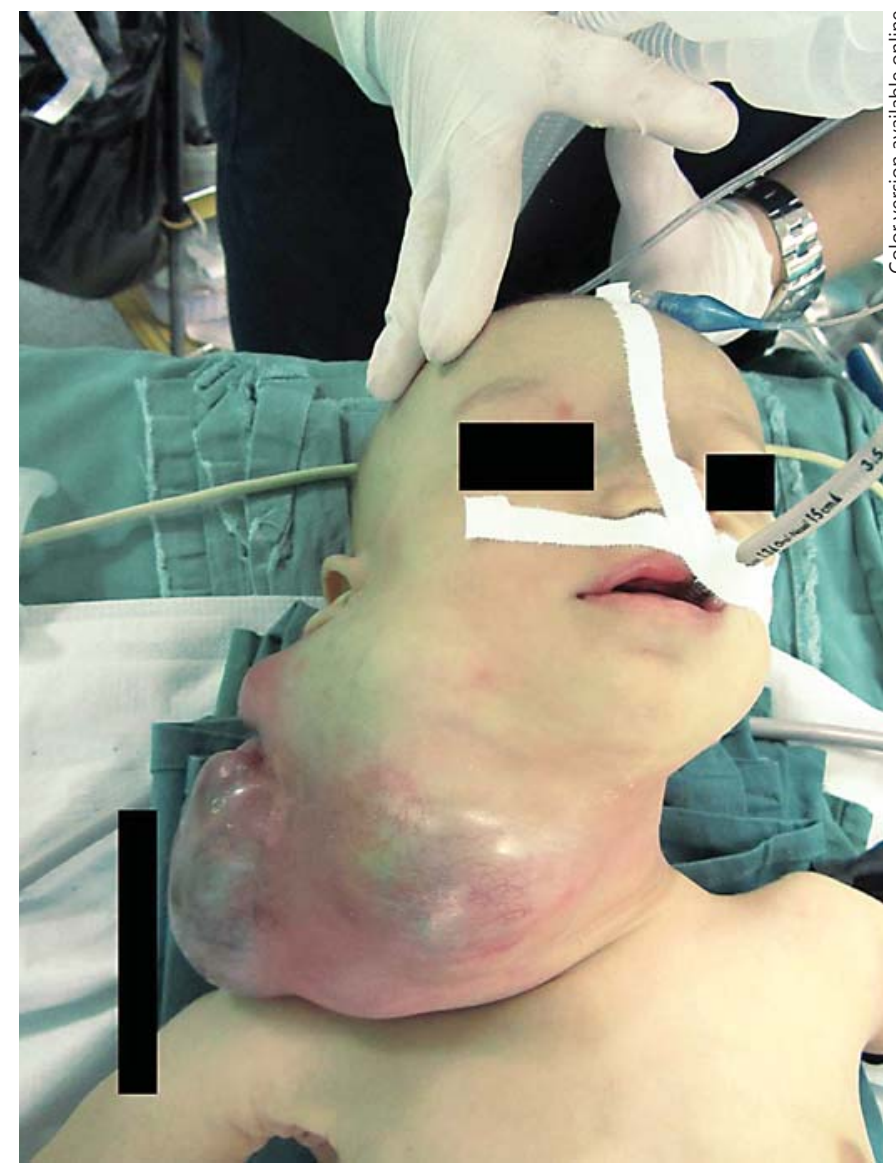

Fig. 1. Large tumor on the right side of the neck.

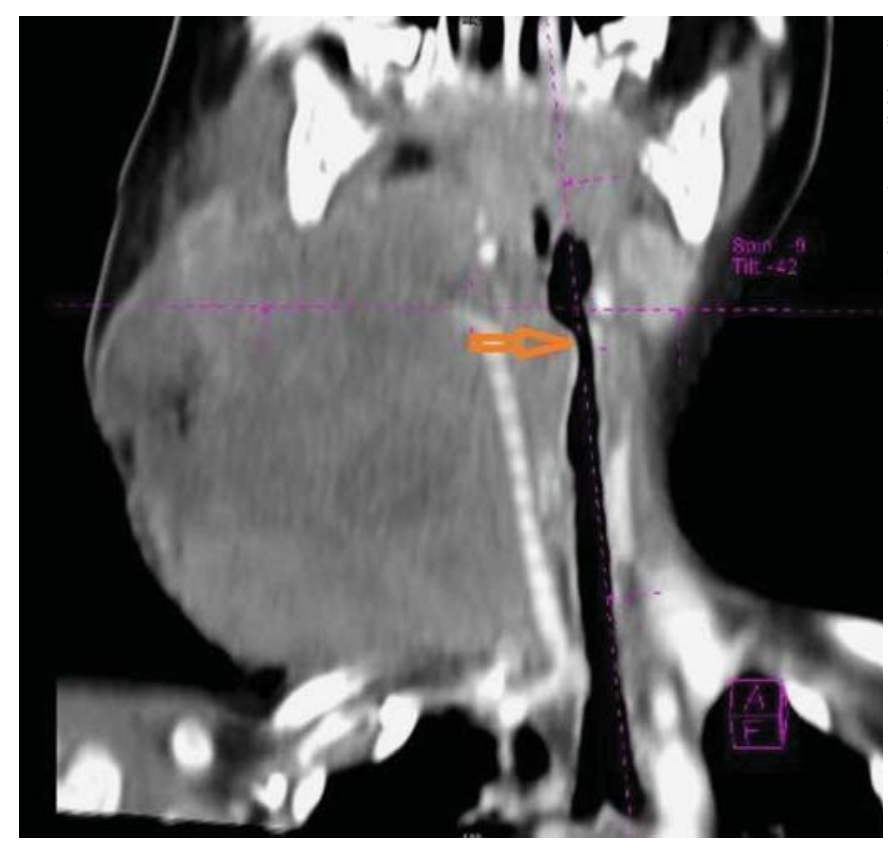

Fig. 2. CT scan showing a dislocated trachea.

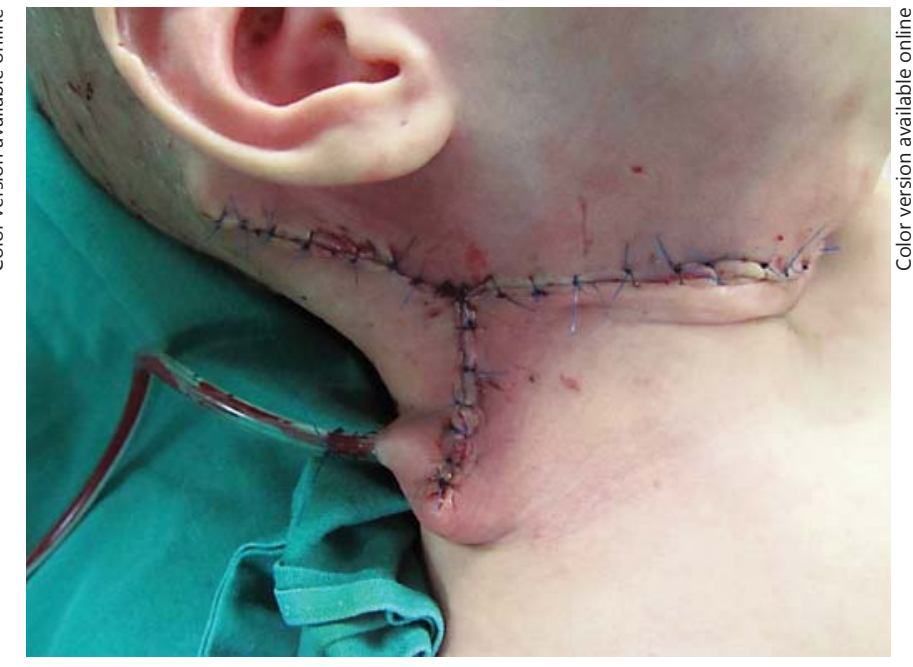

Fig. 3. Postoperative picture: the tumor is nearly $95 \%$ extracted.

normal. The patient had a Mallampati score of III. After atropine and midazolam premedication and preoxygenation, anesthesia was deepened with $1.5-2 \%$ sevoflurane in $100 \%$ oxygen, titrated to maintain spontaneous respiration. Oral laryngoscopy was performed using a Macintosh blade while the patient was breathing spontaneously, and revealed the airway to be Cormack-Lehane grade 3. The trachea was intubated with an armored tube No. 3.5 on the third attempt. After confirming the correct position of the tracheal tube, neuromuscular blockade was achieved with vecuronium bromide. A central venous catheter was placed in the left internal jugular vein, and blood pressure was continuously measured invasively. Anesthesia was than maintained with $1.5 \%$ sevoflurane in air and oxygen (50:50). Analgesia was maintained with intravenous fentanyl, administered after securing the airway. Awake fiberoptic bronchoscope-assisted intubation was planned as an alternative in case mask ventilation and intubation failed. During the operation, which lasted for almost $4 \mathrm{~h}$, the patient received $370 \mathrm{ml}$ of concentrated red blood cells, $400 \mathrm{ml}$ of fresh frozen plasma and 1,200 ml of Hartmann's solution. The intraoperative period was uneventful and macroscopically $95 \%$ of the tumor was removed (fig. 3). After the operation, the patient was transferred to the intensive care unit and extubated $24 \mathrm{~h}$ later.

\section{Discussion}

This case illustrates potential difficulties and challenges in airway management during major surgery in infants with a large neck tumor and the importance of prediction and adequate preoperative preparation. Head and neck masses in children are classified as developmental, inflammatory or neoplastic. Neoplasms of the head and neck account for approximately 5\% of all childhood malignancies. Rhabdoid tumors were originally termed 'rhabdo- 
myosarcomatoid tumors' due to their similar appearance to muscle-based tumors [4]. In the original $1978 \mathrm{Wilms}$ tumor study [5] they were described as very aggressive renal neoplasms. Treatment of MRT is based on chemotherapy, radiotherapy and early surgical resection of the primary tumor if feasible [6]. Unfortunately, limited use of radiotherapy in these very young children leads to poor prognosis, with the survival rate being $17-30 \%$ [7]. Most children with a large neck mass have severe airway compromise (50\% of cases). Airway management in infants with a large neck mass is a challenge for the anesthesiologist in consideration to displaced airway, difficulties in visualizing the airway and risk of sudden complete airway occlusion resulting in hypoventilation, hypoxemia, bradycardia or asystole [8]. Severe hemodynamic effects can occur due to the proximity of magistral blood vessels and decompression induced by surgical removal of a large neck tumor. Providing a safe airway to our patient was a crucial step. Preparation involved careful planning as well as the presence of two experienced anesthesiologists and equipment for a difficult airway that included a fiberoptic bronchoscope [9], laryngeal mask airway, oral and nasal airway, intubation stylet, and tube exchanger. Inhalation induction of anesthesia with sevoflurane was planned to avoid the risk of apnea associated with intravenous agent administration. The intraoperative period was uneventful and after the surgical removal of the tumor, the patient was transferred to the intensive care unit where we used a protocol for difficult airway extubation. Although there were no complications in establishing the airway in our case, it is important to evaluate the airway before the induction of anesthesia and to be prepared for possible difficult airway management.

\section{Conclusion}

Our case shows that the careful preoperative evaluation and anticipation of a difficult airway in an infant with a giant neck mass can minimize the possibility of intraoperative complications. Establishing a safe airway, inhalation induction of anesthesia with sevoflurane, intubation during spontaneous breathing and hemodynamic monitoring to prevent blood loss were crucial factors in the anesthetic management of this case.

\section{Disclosure Statement}

The authors report no conflicts of interest.

\section{References}

1 Bourdeaut F, Freneaux P, Thuille B, et al: Extra-renal non-cerebral rhabdoid tumours. Pediatr Blood Cancer 2008;51:363-368.

$>2$ Dobbs MD, Correa H, Schwarz HS, et al: Extrarenal rhabdoid tumor mimicking a sacral peripheral nerve sheath tumor. Skeletal Radiol 2011;40:1363-1368.

-3 Oda Y, Tsuneyoshi M: Extrarenal rhabdoid tumors of soft tissue: clinicopathological and molecular genetic review and distinction from other soft-tissue sarcomas with rhabdoid features. Pathol Int 2006;56:287-295.
-4 Winger DI, Buyuk A, Bohrer S, et al: Radiology-Pathology Conference: rhabdoid tumor of the kidney. Clin Imaging 2006;30:132-136.

$>5$ Beckwith JB, Palmer NF: Histopatology and prognosis of Wilms tumors: results from the First National Wilms' Tumor Study. Cancer 1978;41:1937-1948.

6 Ronghe MD, Moss TH, Lowis SP: Treatment of CNS malignant rhabdoid tumors. Pediatr Blood Cancer 2004;42:254-260.
Morgenstern DA, Gibson S, Brown T, et al: Clinical and pathological features of pediatric malignant rhabdoid tumours. Pediatr Blood Cancer 2010;54:29-34.

8 Sunder RA, Haile DT, Farrell PT, et al: Pediatric airway management: current practices and future directions. Paediatr Anaesth 2012; 22:1008-1015.

9 Tang LF, Chen ZM: Fiberoptic bronchoscopy in neonatal and pediatric intensive care units: a 5-year experience. Med Princ Pract 2009;18: 305-309. 